\title{
The effect of feto-maternal size and childhood growth on left ventricular mass and arterial stiffness in Afro-Caribbean children
}

\author{
MB Lawrence-Wright ${ }^{1}$, MS Boyne ${ }^{1}$, C Osmond ${ }^{2}$, RA Fraser ${ }^{1}$, S Soares-Wynter ${ }^{1}$, M Thame ${ }^{1}$, \\ M Reid ${ }^{1}$, C Taylor-Bryan ${ }^{1}$ and TE Forrester ${ }^{1}$ \\ ${ }^{1}$ Tropical Medicine Research Institute, University of the West Indies, Mona, Jamaica, West Indies and \\ ${ }^{2}$ Medical Research Council Epidemiology Resource Centre, University of Southampton, Southampton, UK
}

\begin{abstract}
We hypothesized that maternal size, fetal size and childhood growth are associated with childhood blood pressure, left ventricular mass (LVM) and arterial stiffness. The Vulnerable Windows Cohort is a longitudinal study of 569 mothers and their offspring. Anthropometry was measured on each child at birth, at 6 weeks, once in 3 months upto 2 years and then every 6 months. Blood pressure and body composition were assessed in 185 children (age 11.5 years) and echocardiography performed. LVM was not associated with maternal size after adjustment for child's weight. LVM was significantly associated with faster growth in childhood and with current weight, fat mass and lean mass. Systolic blood pressure was not related to maternal, fetal or
\end{abstract}

newborn anthropometry, but was positively associated with infant and childhood growth, as well as current body size and fat mass. The pulse pressure/stroke volume ratio (an index of arterial stiffness) was inversely associated with maternal size, placental volume at 20 weeks, fetal size at 35 weeks and childhood growth even after adjustment for current weight. In conclusion, LVM in childhood is positively associated with maternal height, child's current size and rate of growth. Arterial stiffness is inversely related to maternal, fetal and placental size as well as growth throughout childhood.

Journal of Human Hypertension (2011) 25, 457-464; doi:10.1038/jhh.2010.84; published online 19 August 2010

Keywords: left ventricular mass; arterial stiffness; fetus; growth; blood pressure

\section{Introduction}

Myocardial hypertrophy, most frequently due to hypertension in adults, is associated with several risk factors that operate at different times across the life course. These include the intrauterine changes in cardiovascular mechanics that redistribute blood flow from body to brain in the presence of fetal growth retardation. ${ }^{1-6}$ In later life, left ventricular hypertrophy is a strong predictor of stroke, heart failure and coronary artery disease. ${ }^{7}$

Growth in infancy and childhood also appear to modulate the risk of hypertension, stroke and coronary artery disease, and thus might relate to left ventricular hypertrophy. ${ }^{8,9}$ Left ventricular hypertrophy is causally related to mechanical loading whether characterized by blood pressure, wave

Correspondence: Professor TE Forrester, Tropical Metabolism Research Unit, Tropical Medicine Research Institute, University of the West Indies, Mona, Kingston 7, Jamaica, West Indies.

E-mail: terrence.forrester@uwimona.edu.jm

Received 11 February 2010; revised 9 June 2010; accepted 28 June 2010; published online 19 August 2010 mechanics or indices of arterial stiffness, such as arterial pulse wave velocity and compliance. ${ }^{10,11}$ However, arterial stiffness has also been shown to be an independent risk factor for fatal and non-fatal cardiovascular events both in patients with hypertension and in the general population. ${ }^{12-14}$

The risk of coronary artery disease, stroke and other vascular pathology is reportedly increased in the offspring of mothers who were undernourished while they were pregnant. ${ }^{15}$ As preclinical markers, such as left ventricular hypertrophy and arterial stiffness, ${ }^{13}$ are such powerful predictors of future vascular pathology, we hypothesized that maternal, fetal, placental, newborn size as well as growth in infancy and childhood would be associated with left ventricular mass (LVM) or its determinants, blood pressure and pulse pressure/stroke volume ratio, an index of arterial stiffness.

\section{Methods}

Subjects and study design

As previously described, ${ }^{16} 712$ women attending the antenatal clinic at the University Hospital of the 
West Indies, Kingston, Jamaica, were invited to participate in a prospective study of intrauterine growth, and risk factors for chronic cardiovascular disease in later life. Inclusion criteria were the following: women who were aged between 15 and 40 years, were 7-10 weeks pregnant (which was confirmed by a 14-week ultrasound) and without systemic illnesses (for example, pre-eclampsia and diabetes) or genetic abnormality (for example, sickle cell disease). Only 17 (3.5\%) of the mothers smoked. The 712 women yielded 569 babies to the cohort: 82 had pregnancy losses; 56 withdrew for reasons such as work constraints and migration; and five sets of twins were excluded. This study is confined to the 185 children who accepted an invitation to have echocardiographic measurements. The Ethics Committee of the University of the West Indies approved the study, and each mother gave written informed consent.

\section{Measurements}

Maternal and feto-placental anthropometry. Using a standardized protocol, ${ }^{16}$ maternal weight was measured to the nearest $0.01 \mathrm{~kg}$ and height was measured to the nearest $0.1 \mathrm{~cm}$. Abdominal ultrasound was performed using a linear probe (ATL Ultramark IV, Advanced Technology Labs, Bothell, WA, USA) at 14, 17, 20, 25, 30 and 35 weeks of gestation. Fetal head and abdominal circumferences were measured in triplicate at all six visits, and the average for each visit was used. Placental volume was measured sonographically at 14,17 and 20 weeks. ${ }^{16}$ The long axis of the placenta was identified and a continuous recording of the image of the placenta orthogonal to the axis was carried out. This axis was divided into six sections of equal length; the five interior cross-sectional areas were measured and integrated to estimate placental volume.

Offspring anthropometry and blood pressure Birth weight, crown-heel length, head circumference and placental weight were measured within $24 \mathrm{~h}$ of delivery. We measured anthropometry at 6 weeks, once in 3 months upto 2 years and then every 6 months. Blood pressure was measured every 6 months from the age of 1 year using a mercury sphygmomanometer (Baumanometer, Copiague, NY, USA). Two readings were taken with the child in the seated position and the average used. Inter- and intra-observer variabilities were measured every 3 months, followed by training/recertification for any observer whose scores were not acceptable.

Assessment of pubertal stage was performed every 6 months starting at age 8 years. Girls were asked at each clinic visit whether they had started their menses and, if so, at what age. Pubic hair and breast development were measured according to the method of Marshall and Tanner., ${ }^{17,18}$ Testicular volume was measured with a Prader orchidometre, with volumes ranging from 1 to $25 \mathrm{ml}$.

Body composition at mean age 11.5 years was measured using single frequency bioelectrical impedance analyzer ( $50 \mathrm{KHz}$ model 101Q RJL Systems, Clinton Twp, MI, USA) in the supine position. The mean of two measurements was used in the calculations. Lean mass and fat mass were estimated from the manufacturer's equations.

\section{Two-dimensional transthoracic echocardiography}

Cardiac structure and function was assessed using transthoracic echocardiography at age $11.5 \pm 1.3$ years using ATL Ultramark 7 (Advanced Technology Labs) and Philips iE33 phased-array echocardiogram machines. Parasternal views were obtained with optimal orientation to maximize left ventricular internal dimensions; and apical views obtained to evaluate optimal trans-mitral and trans-aortic Doppler signals. Left ventricular internal dimensions and wall thicknesses were measured from the M-mode left ventricular recordings at end-diastole, according to the American Society of Echocardiography recommendations. ${ }^{19}$ When optimal orientation of M-mode left ventricular recordings were not obtained, linear left ventricular measurements were taken from the two-dimensional images, using the leading-edge convention. These linear measurements were then used to determine LVM, geometry and systolic function. Doppler measurements were used to assess left ventricular diastolic function. Together with the participant's blood pressure and heart rate, ventricular linear measurements were used to estimate participant systemic haemodynamics.

We used the pulse pressure/stroke volume ratio as a measure of arterial stiffness. ${ }^{20,21}$ This surrogate of arterial stiffness is easy to measure and is based on a Windkessel model of the arterial tree. It is highly correlated $(r=0.85)$ with the ratio of the diastolicdecay time constant (tau) of the arterial system and the peripheral resistance ${ }^{14}$ and has been shown to predict cardiovascular events both in hypertensive patients ${ }^{12}$ and in the general population ${ }^{21}$. The pulse pressure/stroke volume ratio is calculated by dividing the brachial pulse pressure (that is, brachial systolic minus diastolic blood pressure) as measured by mercury sphygmomanometer by the left ventricular stroke volume (that is, end-diastolic minus end-systolic volume) as determined from linear echocardiographic left ventricular measurements.

\section{Statistical analyses}

Body mass index (BMI) was calculated as weight in $\mathrm{kg}$ divided by the square of the height in metres. Growth (that is, gains in weight, height and BMI) was measured in three time intervals: birth to 6 months; 6 months to 2 years; and 2 years to age 11 years. Growth was defined as the amount by which 
the size at the end of a time interval exceeded that which would have been predicted by linear regression using the measurements available at the beginning of the interval. ${ }^{14}$ Such measures are uncorrelated by construction. Simple differences in $z$-score do not have this property, as a large difference may result from either a low value at the beginning of the interval or a high one at the end. ${ }^{22}$

Multiple regression analyses were used to examine the relationships among maternal, placental, fetal and neonatal measurements with LVM, systolic blood pressure and pulse pressure to stroke volume ratio in the 185 children. Variables were log transformed to normality. We used outcomes and predictors in standardized form. We evaluated for interactions by sex to see if the regression coefficients were similar in boys and girls, so we used product terms of sex with anthropometric variables. We always adjusted risk factors for age at the clinic visit. A $P$-value $<0.05$ was considered statistically significant. SPSS 15.0 for Windows (Chicago, IL, USA) was used for the statistical analyses.

\section{Results}

The 185 subjects studied were similar to the other members of the cohort in maternal age, height, weight and BMI. At birth, they were not different in crown-heel length, head circumference, placental weight or gestational age at delivery, but were $120 \mathrm{~g}$ heavier $(P=0.02)$.

Mean values for maternal, placental, fetal and newborn measurements as well as childhood anthropometry and cardiovascular measurements are shown in Table 1. As expected, the boys were larger until age 11 years, at which stage more girls had started their pubertal growth spurt and had a higher BMI, fat mass and percent body fat. The median age at reaching Tanner stage 3 for pubic hair development was 11.1 years in girls and 12.8 years in boys.

Table 2 shows the associations of LVM, systolic blood pressure and pulse pressure/stroke volume with maternal, placental, fetal and newborn size. Table 3 describes the associations of these outcomes with infant and childhood growth. Table 4 shows the associations of the outcomes with various measures of current size after adjustment for sex and current age. We describe the outcomes in sequence.

\section{LVM}

LVM was positively associated with maternal height measured in the first trimester (Table 2). The relationship of LVM with maternal height was however lost after adjustment for child's weight. LVM was also related to growth in childhood, that is, gains in height, weight and BMI that were greater than predicted (Table 3 Figure 1a). LVM was
Table 1 Maternal, placental, fetal, birth, infant and childhood measurements

\begin{tabular}{|c|c|c|c|c|}
\hline & \multicolumn{2}{|c|}{ Boys $(\mathrm{n}=86)$} & \multicolumn{2}{|c|}{ Girls $(\mathrm{n}=99)$} \\
\hline & Mean & s.d. & Mean & s.d. \\
\hline \multicolumn{5}{|l|}{ Maternal measurements (first trimester) } \\
\hline Age (years) & 27.0 & 5.7 & 26.3 & 5.1 \\
\hline Height (cm) & 163.5 & 5.9 & 163.0 & 5.9 \\
\hline Weight (kg) & 66.7 & 12.8 & 65.6 & 13.4 \\
\hline $\begin{array}{l}\text { Pregnancy weight gain (kg per } \\
4 \text { weeks) }\end{array}$ & 1.3 & 0.6 & 1.4 & 0.7 \\
\hline \multicolumn{5}{|l|}{ Placental measurements } \\
\hline 14 week volume (ml) & 128 & 59 & 114 & 58 \\
\hline 17 week volume (ml) & 250 & 75 & 242 & 80 \\
\hline 20 week volume (ml) & 373 & 82 & 364 & 89 \\
\hline Weight at delivery (g) & 601 & 147 & 566 & 115 \\
\hline \multicolumn{5}{|l|}{ Fetal abdominal circumference (mm) } \\
\hline 14 week & 87.2 & 11.9 & 85.0 & 13.5 \\
\hline 25 week & 209.1 & 12.7 & 205.3 & 16.2 \\
\hline 35 week & 319.2 & 16.5 & 311.7 & 18.7 \\
\hline \multicolumn{5}{|l|}{ Birth measurements } \\
\hline Weight (g) & 3278 & 502 & 3123 & 474 \\
\hline Length (cm) & 49.9 & 2.9 & 49.3 & 3.0 \\
\hline Head circumference (cm) & 32.9 & 2.1 & 32.4 & 2.3 \\
\hline Gestational age (days) & 274.4 & 12.2 & 274.6 & 13.0 \\
\hline \multicolumn{5}{|l|}{ Size at age 6 months } \\
\hline Weight (kg) & 8.2 & 0.9 & 7.7 & 0.9 \\
\hline Height (cm) & 67.7 & 2.1 & 66.3 & 2.1 \\
\hline \multicolumn{5}{|l|}{ Size at age 2 years } \\
\hline Weight (kg) & 12.3 & 1.3 & 11.8 & 1.5 \\
\hline Height $(\mathrm{cm})$ & 87.2 & 2.9 & 87.0 & 2.8 \\
\hline \multicolumn{5}{|l|}{ Size at age 11 years } \\
\hline Weight (kg) & 37.6 & 7.7 & 42.0 & 8.9 \\
\hline Height $(\mathrm{cm})$ & 146.4 & 6.0 & 150.1 & 6.5 \\
\hline \multicolumn{5}{|l|}{ Clinic measurements } \\
\hline Age (years) & 10.9 & 0.9 & 11.0 & 1.0 \\
\hline Height $(\mathrm{cm})$ & 149.3 & 9.0 & 152.2 & 10.1 \\
\hline Weight (kg) & 41.5 & 9.8 & 46.1 & 12.9 \\
\hline Body mass index $\left(\mathrm{kg} \mathrm{m}^{-2}\right)$ & 18.5 & 3.3 & 19.7 & 4.3 \\
\hline Waist circumference (cm) & 66.6 & 7.5 & 68.7 & 9.5 \\
\hline Lean mass (kg) & 30.4 & 6.4 & 29.9 & 6.6 \\
\hline Fat mass $(\mathrm{kg})$ & 11.1 & 6.7 & 16.2 & 8.5 \\
\hline Fat percentage (\%) & 25.4 & 10.2 & 33.4 & 9.7 \\
\hline \multicolumn{5}{|l|}{ Cardiac measurements at age 11 years } \\
\hline Left ventricular mass (g) & 85.1 & 22.0 & 85.3 & 23.2 \\
\hline Systolic blood pressure (mm Hg) & 100.1 & 6.2 & 99.5 & 5.1 \\
\hline Diastolic blood pressure (mm Hg) & 53.0 & 4.0 & 51.4 & 3.1 \\
\hline Stroke volume $(\mathrm{ml})$ & 50.5 & 11.2 & 50.3 & 11.4 \\
\hline $\begin{array}{l}\text { Pulse pressure per stroke volume } \\
\left(\mathrm{mm} \mathrm{Hg} \mathrm{ml}^{-1}\right)\end{array}$ & 0.98 & 0.27 & 1.01 & 0.26 \\
\hline
\end{tabular}

strongly correlated with all anthropometric and body composition measurements (Table 4), most strongly with current weight. As boys and girls had progressed to varying degrees through puberty, we adjusted for pubertal stage. Again, after adjustment for current weight, pubertal stage made no contribution to LVM (data not shown). Expressing LVM as the LVM index (LVM/height ${ }^{2.7}$ ) did not alter these relationships. 
Table 2 Regression coefficients between maternal, placental, fetal and birth measurements of 185 Jamaican children and their left ventricular mass (LVM), systolic blood pressure (SBP), pulse pressure/stroke volume (PPSV)

\begin{tabular}{|c|c|c|c|c|c|c|}
\hline & \multicolumn{3}{|c|}{ Adjusted for age and sex } & \multicolumn{3}{|c|}{ Adjusted for age, sex and weight } \\
\hline & $L V M$ & $S B P$ & PPSV & $L V M$ & $S B P$ & $P P S V$ \\
\hline \multicolumn{7}{|l|}{ Maternal measurements } \\
\hline Age at booking & 0.082 & -0.036 & -0.037 & 0.073 & -0.047 & -0.029 \\
\hline Height & $0.181^{\mathrm{a}}$ & 0.056 & $-0.168^{\mathrm{a}}$ & 0.126 & 0.017 & -0.134 \\
\hline Weight at booking & 0.126 & -0.003 & $-0.201^{\mathrm{a}}$ & 0.074 & -0.040 & $-0.174^{\mathrm{a}}$ \\
\hline Body mass index at booking & 0.070 & -0.022 & $-0.154^{\mathrm{a}}$ & 0.032 & -0.048 & -0.135 \\
\hline Pregnancy weight gain & 0.073 & 0.093 & -0.060 & 0.071 & 0.091 & -0.057 \\
\hline Socioeconomic status & 0.042 & 0.011 & 0.053 & 0.068 & 0.023 & 0.043 \\
\hline \multicolumn{7}{|l|}{ Placental measurements } \\
\hline 14-week volume & -0.010 & -0.069 & -0.137 & -0.033 & -0.083 & -0.130 \\
\hline 17-week volume & -0.014 & -0.148 & -0.129 & 0.001 & -0.144 & -0.141 \\
\hline 20-week volume & 0.093 & -0.080 & $-0.208^{\mathrm{a}}$ & 0.083 & -0.093 & $-0.204^{\mathrm{a}}$ \\
\hline Weight at delivery & 0.040 & 0.037 & -0.088 & 0.020 & 0.025 & -0.078 \\
\hline \multicolumn{7}{|l|}{ Fetal measurements } \\
\hline 14 week: abdominal circulation & -0.029 & 0.051 & 0.084 & 0.023 & 0.083 & 0.058 \\
\hline Femoral length & -0.043 & 0.076 & 0.096 & -0.002 & 0.104 & 0.075 \\
\hline Head circulation & -0.090 & -0.051 & -0.037 & -0.040 & -0.020 & -0.070 \\
\hline 25 week: abdominal circulation & 0.035 & 0.010 & -0.072 & 0.097 & 0.042 & -0.016 \\
\hline Femoral length & -0.001 & -0.002 & -0.058 & 0.033 & 0.017 & -0.078 \\
\hline Head circulation & 0.015 & -0.037 & -0.053 & 0.075 & -0.006 & -0.086 \\
\hline 35 week: abdominal circulation & -0.048 & 0.010 & -0.073 & -0.025 & -0.029 & $-0.215^{\mathrm{a}}$ \\
\hline Femoral length & -0.011 & -0.076 & $-0.211^{\mathrm{a}}$ & -0.020 & -0.083 & $-0.213^{\mathrm{a}}$ \\
\hline Head circulation & 0.010 & -0.097 & $-0.218^{\mathrm{a}}$ & 0.070 & -0.069 & $-0.258^{\mathrm{a}}$ \\
\hline \multicolumn{7}{|l|}{ Birth measurements } \\
\hline Weight & 0.032 & -0.016 & -0.124 & 0.001 & -0.036 & -0.109 \\
\hline Length & -0.047 & -0.142 & -0.092 & -0.053 & -0.148 & -0.094 \\
\hline Body mass index & 0.079 & 0.078 & -0.060 & 0.050 & 0.060 & -0.042 \\
\hline Head circulation & -0.009 & -0.075 & -0.103 & -0.029 & -0.088 & -0.096 \\
\hline Gestation at delivery & 0.013 & -0.029 & -0.069 & 0.002 & -0.036 & -0.064 \\
\hline
\end{tabular}

Variables are in standardized form. Each cell corresponds to a different regression analysis.

${ }^{\mathrm{a}}$ Corresponds to $P<0.05$.

bWeight refers to child's current weight.

Systolic blood pressure

Systolic blood pressure was not significantly related to any maternal, fetal or newborn anthropometric measurement (Table 2). However, it was positively correlated with gains in height, weight and BMI after age 6 months till age 11 years (Table 3 and Figure 1b). Systolic blood pressure was also directly related to the child's weight, BMI, waist circumference and fat mass (Table 4). After adjusting for current weight, pubertal stage did not account for any of the variance in systolic blood pressure (data not shown).

Pulse pressure/stroke volume ratio

Pulse pressure/stroke volume ratio was inversely associated with maternal height, weight and BMI during the first trimester. It was also negatively associated with the placental volume measured at 20 weeks, and fetal femoral length and head circumference measured at 35 weeks gestation (Table 2). These associations remained relatively similar after adjustment for child current weight and maternal size (data not shown). The ratio was inversely related to childhood growth, especially after age 2 years (Table 3 and Figure 1c), as well as current weight and body composition (Table 4). After adjustment for current weight, the association of pubertal stage with the pulse pressure/stroke volume ratio was not significant (data not shown).

\section{Discussion}

This longitudinal cohort study provides additional evidence for the developmental programming of preclinical markers of cardiovascular disease in a cohort of Afro-Jamaican children followed from intrauterine life through to mean age 11.5 years. LVM was not independently associated with maternal or fetal markers of early development, but rather was determined by child's weight. However, arterial stiffness, which is a major predictor of left ventricular concentric hypertrophy in adults, ${ }^{12,20,21,23}$ was strongly related to small size in mother, placenta and fetus as well as slower growth throughout 
Table 3 Regression coefficients between the size at birth and childhood growth of 185 Jamaican children and their cardiovascular measurements after adjustment for sex and current age

\begin{tabular}{lccc}
\hline $\begin{array}{l}\text { Measurement of } \\
\text { size and growth }\end{array}$ & $\begin{array}{c}\text { Left } \\
\text { ventricular } \\
\text { mass }\end{array}$ & $\begin{array}{c}\text { Systolic } \\
\text { blood } \\
\text { pressure }\end{array}$ & $\begin{array}{c}\text { Pulse } \\
\text { pressure/ } \\
\text { stroke volume }\end{array}$ \\
\hline Height & & & \\
$\quad$ Size at birth & -0.025 & -0.134 & -0.117 \\
Growth: 0-6 months & $0.187^{\mathrm{a}}$ & 0.132 & $-0.213^{\mathrm{a}}$ \\
Growth: 6 months-2 & $0.209^{\mathrm{a}}$ & $0.281^{\mathrm{b}}$ & -0.093 \\
years & & & \\
Growth: 2-11 years & $0.244^{\mathrm{b}}$ & 0.108 & $-0.186^{\mathrm{a}}$ \\
& & & \\
Weight & 0.041 & 0.005 & -0.132 \\
Size at birth & $0.144^{\mathrm{a}}$ & 0.094 & -0.132 \\
$\quad$ Growth: 0-6 months & $0.229^{\mathrm{b}}$ & $0.305^{\mathrm{b}}$ & -0.095 \\
Growth: 6 months-2 & & & \\
years & $0.392^{\mathrm{b}}$ & $0.198^{\mathrm{a}}$ & $-0.211^{\mathrm{a}}$ \\
Growth: 2-11 years & & & \\
Body mass index & & & \\
Size at birth & 0.076 & 0.097 & -0.056 \\
$\quad$ Growth: 0-6 months & $0.137^{\mathrm{a}}$ & 0.044 & -0.069 \\
Growth: 6 months-2 & 0.125 & $0.170^{\mathrm{a}}$ & -0.016 \\
years & & & \\
Growth: 2-11 years & $0.371^{\mathrm{b}}$ & $0.240^{\mathrm{a}}$ & $-0.168^{\mathrm{a}}$ \\
\hline
\end{tabular}

All variables are in standardized form.

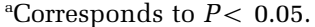

${ }^{\mathrm{b}}$ Corresponds to $P<0.001$.

Table 4 Regression coefficients between measurements of current size of 185 Jamaican children and their cardiovascular measurements after adjustment for sex and current age

\begin{tabular}{lccc}
\hline & $\begin{array}{c}\text { Left } \\
\text { ventricular } \\
\text { mass }\end{array}$ & $\begin{array}{c}\text { Systolic } \\
\text { blood } \\
\text { pressure }\end{array}$ & $\begin{array}{c}\text { Pulse } \\
\text { pressure/ } \\
\text { stroke volume }\end{array}$ \\
\hline Weight & $0.421^{\mathrm{a}}$ & $0.256^{\mathrm{a}}$ & $-0.239^{\mathrm{a}}$ \\
Height & $0.201^{\mathrm{a}}$ & 0.092 & $-0.230^{\mathrm{a}}$ \\
Body mass index & $0.404^{\mathrm{a}}$ & $0.261^{\mathrm{a}}$ & $-0.170^{\mathrm{a}}$ \\
Body surface area $_{\text {Height }}^{2.7}$ & $0.396^{\mathrm{a}}$ & 0.229 & $-0.263^{\mathrm{a}}$ \\
Lean mass & $0.201^{\mathrm{a}}$ & 0.081 & $-0.228^{\mathrm{a}}$ \\
Waist circumference & $0.231^{\mathrm{a}}$ & 0.173 & $-0.245^{\mathrm{a}}$ \\
Fat mass & $0.387^{\mathrm{a}}$ & $0.255^{\mathrm{a}}$ & -0.164 \\
Percentage fat & $0.422^{\mathrm{a}}$ & $0.233^{\mathrm{a}}$ & -0.155 \\
& $0.345^{\mathrm{a}}$ & 0.167 & -0.070 \\
\hline
\end{tabular}

All variables are in standardized form.

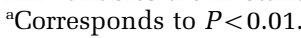

childhood. The associations with placental and fetal factors remained significant even after adjustment for maternal size.

Birth size is correlated with LVM at age 1 year, ${ }^{24}$ but this effect seems to be attenuated by age 2 years. ${ }^{25}$ Intrauterine growth retardation has been associated with increased LVM in childhood, but some of this effect may be confounded by prematurity itself. ${ }^{26}$ In Dutch children maternal weight gain in late pregnancy, but not maternal size, was related to LVM in infancy. ${ }^{2}$ We found that by late childhood, LVM was not dependent on birth size, but was dependent on the current size of the child, and these data are consistent with that of other

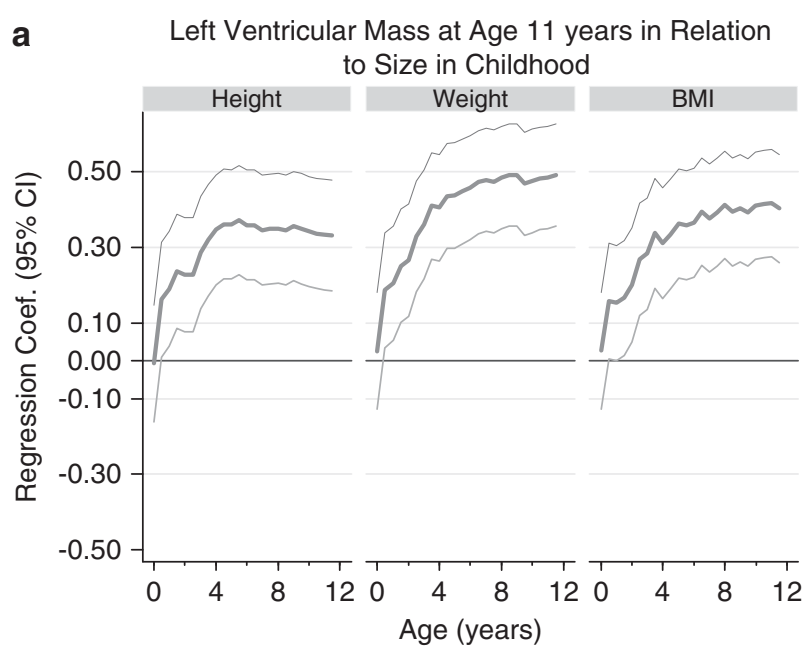

b Systolic Blood Pressure at Age 11 years in Relation to Size in Childhood

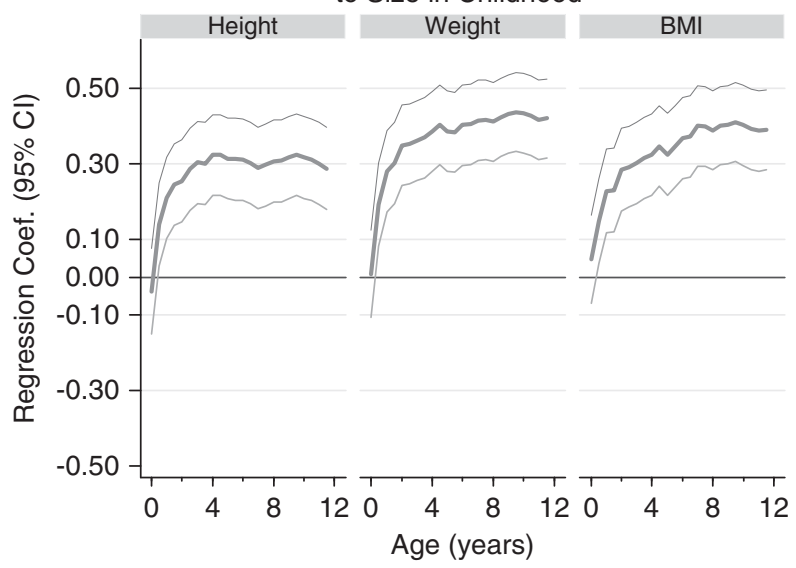

C Pulse Pressure/Stroke Volume Ratio at Age 11 years

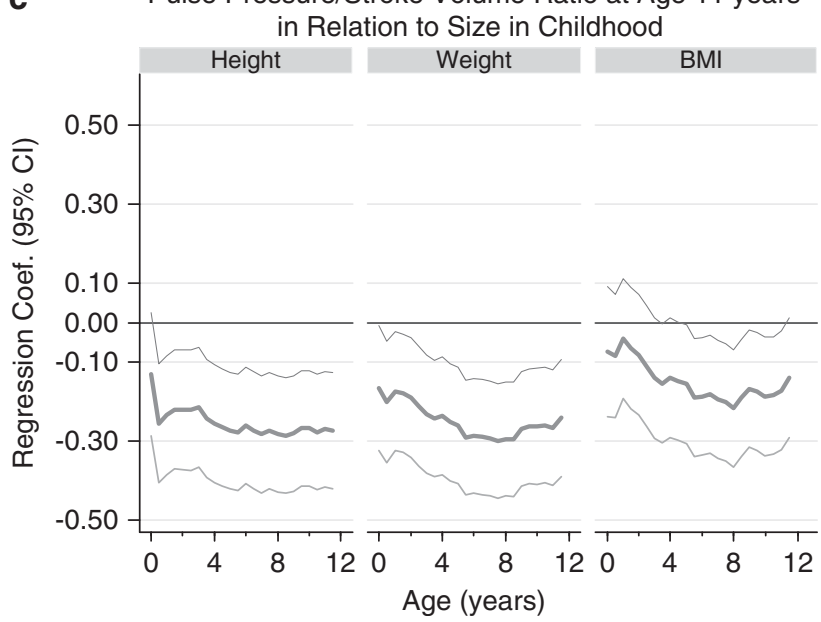

Figure 1 Regression coefficients and their 95\% confidence intervals (CIs) of (a) left ventricular mass (LVM), (b) systolic blood pressure and (c) pulse pressure/stroke volume on height, weight and body mass index (BMI) of 185 Jamaican children at age 11 years in relation to size in childhood. Analyses are adjusted for sex. Variables are analysed in standardized units.

investigators. ${ }^{25,27}$ The effect of maternal size on LVM in their children was mediated by child's attained weight, and accelerated growth during infancy and 
childhood was associated with greater LVM. Some of our findings are comparable with those of Kumaran et al. ${ }^{28}$ In their study of middle-aged Indians, there was no relation between birth size and blood pressure, arterial compliance or LVM. Decreased maternal size and pelvic diameter were however associated with decreased arterial compliance, as derived from non-invasive optical measurement of pulse wave velocity.

Although current size correlates with LVM, it is not clear if fat mass or lean mass may be the driver of ventricular growth. Both appear to be determinants in American children, but lean mass has a stronger effect. $^{29,30}$ However, the size of the regression coefficients in our data suggest that fat mass has a larger effect in our cohort of Jamaican children.

Our data are consistent with other investigators who found that children with intrauterine growth retardation or who were born small for gestational age have abnormal arterial stiffness even if their blood pressure is normal. ${ }^{31,32}$ Current size also has a major role, as arterial stiffness in children is increased by adiposity ${ }^{33}$ and in the presence of features of the metabolic syndrome. ${ }^{34,35}$ In fact, ethnic differences in arterial stiffness are mostly explained by differences in adiposity, ${ }^{36,37}$ which itself may have early life origins ${ }^{38}$.

A developmental contribution to cardiovascular structure and function has been proposed and potential mechanisms mooted..$^{2,39-43}$ Intrauterine undernutrition may cause hypercortisolaemia, which can cause accelerated cardiac ontogeny, tipping the balance to cardiac fibrosis, and in turn giving rise to cardiac dysfunction. ${ }^{39}$ In addition, early pressure loading of cardiac myocytes may lead to fewer but larger myocytes. ${ }^{40}$ Large artery elasticity is dependent on elastin, which is laid down in utero and during infancy. Intrauterine undernutrition causes shunting of blood flow from the trunk to the brain, and reduces elastin deposition in the large arteries of the trunk and legs, making these vessels less compliant and facilitating the development of hypertension in adult life. ${ }^{41,42}$ Also, upregulation of matrix metalloproteinases-2 and -9 increases arterial stiffness by degrading elastic fibre, as well as inhibiting angiogenesis by generating angiostatin in diabetic persons. ${ }^{43}$ It is possible that inhibited fetal growth could also lead to similar effects. In support, children with lower birth weights also have smaller coronary artery, aortic root and left ventricular outflow tract diameters, and these changes in association with a greater predisposition to hypertension would increase the risk for coronary heart disease. ${ }^{44}$ The additional effect of rapid postnatal growth on ventricular mass would be of prognostic significance as LVM appears to track over time; ${ }^{45,46}$ these effects would be expected to persist into later life. ${ }^{47}$

Unfortunately, we do not have concurrent dietary and physical activity data for this cohort, both of which can influence arterial stiffness. High-dietary fat intake is associated with rapid postnatal growth and increased arterial stiffness. ${ }^{48}$ Arterial stiffness in children can be reversed by a regular physical activity programme, which also delays arterial wall remodelling. ${ }^{49,50}$ The combination of diet and cardiorespiratory fitness may be even more useful. ${ }^{51}$

The strengths of our study include its prospective, longitudinal design and the standardized manner in which the measurements were performed. One limitation however is that arterial stiffness was measured at clinic only. Echocardiographic pulse pressure/stroke volume index is however recognized as a good surrogate for arterial stiffness estimated using other more direct techniques, such as tonometry. ${ }^{20,52,53}$ This measure is more than adequate to rank subjects.

In this study, therefore, LVM in childhood is positively associated with maternal height, child's current size and child's rate of growth. Arterial stiffness, a marker of the future risk of left ventricular hypertrophy, is inversely related to maternal, fetal and placental size as well as growth throughout childhood. As the capacity to respond to vascular challenges in adulthood is dependent upon cardiovascular development during childhood, one avenue of prevention might focus on this developmental period.

\footnotetext{
What is known about topic

- Growth in utero, infancy and childhood may influence the risk of hypertension and atherosclerotic disease.

- It is unclear if maternal factors and offspring growth are related to preclinical markers of atherosclerotic disease, such as left ventricular mass and arterial stiffness.

What this study adds

- Maternal size, through its influence on child's weight, is positively related to left ventricular mass in children.

- Arterial stiffness is inversely related to maternal, fetal and placental size as well as growth throughout childhood.
}

\section{Conflict of interest}

The authors declare no conflict of interest.

\section{Acknowledgements}

This study was supported by a grant from the Wellcome Trust, 183 Euston Road, London, England, and funding from the University of the West Indies.

\section{References}

1 Ahuja P, Sdek P, MacLellan WR. Cardiac myocyte cell cycle control in development, disease, and regeneration. Physiol Rev 2007; 87(2): 521-544.

2 Geelhoed JJ, van Osch-Gevers L, Verburg BO, Steegers EA, Hofman A, Helbing $\mathrm{W}$ et al. Maternal 
anthropometrics in pregnancy are associated with left ventricular mass in infancy. The generation $\mathrm{R}$ study. Pediatr Res 2008; 63(1): 62-66.

3 Battista MC, Calvo E, Chorvatova A, Comte B, Corbeil J, Brochu $M$. Intra-uterine growth restriction and the programming of left ventricular remodelling in female rats. J Physiol 2005; 565(Part 1): 197-205.

4 de Simone G, Pasanisi F, Contaldo F. Link of nonhemodynamic factors to hemodynamic determinants of left ventricular hypertrophy. Hypertension 2001; 38(1): 13-18.

5 Kawamura M, Itoh H, Yura S, Mogami H, Suga S, Makino $\mathrm{H}$ et al. Undernutrition in utero augments systolic blood pressure and cardiac remodeling in adult mouse offspring: possible involvement of local cardiac angiotensin system in developmental origins of cardiovascular disease. Endocrinology 2007; 148(3): 1218-1225.

6 Vonnahme KA, Hess BW, Hansen TR, McCormick RJ, Rule DC, Moss GE et al. Maternal undernutrition from early- to mid-gestation leads to growth retardation, cardiac ventricular hypertrophy, and increased liver weight in the fetal sheep. Biol Reprod 2003; 69(1): 133-140.

7 Gradman AH, Alfayoumi F. From left ventricular hypertrophy to congestive heart failure: management of hypertensive heart disease. Prog Cardiovasc Dis 2006; 48(5): 326-341.

8 Barker DJ, Osmond C, Kajantie E, Eriksson JG. Growth and chronic disease: findings in the Helsinki Birth Cohort. Ann Hum Biol 2009; 36(5): 445-458.

9 Adair LS, Martorell R, Stein AD, Hallal PC, Sachdev HS, Prabhakaran D et al. Size at birth, weight gain in infancy and childhood, and adult blood pressure in 5 low- and middle-income-country cohorts: when does weight gain matter? Am J Clin Nutr 2009; 89(5): 1383-1392.

10 Opie LH, Commerford PJ, Gersh BJ, Pfeffer MA. Controversies in ventricular remodelling. Lancet 2006; 367(9507): 356-367.

11 Segers P, Rietzschel ER, De Buyzere ML, Vermeersch SJ, De Bacquer D, Van Bortel LM et al. Noninvasive (input) impedance, pulse wave velocity, and wave reflection in healthy middle-aged men and women. Hypertension 2007; 49(6): 1248-1255.

12 de Simone G, Roman MJ, Koren MJ, Mensah GA, Ganau A, Devereux RB. Stroke volume/pulse pressure ratio and cardiovascular risk in arterial hypertension. Hypertension 1999; 33(3): 800-805.

13 Amar J, Ruidavets JB, Chamontin B, Drouet L, Ferrieres J. Arterial stiffness and cardiovascular risk factors in a population-based study. J Hypertens 2001; 19(3): 381-387.

14 Kajantie E, Barker DJ, Osmond C, Forsen T, Eriksson JG. Growth before 2 years of age and serum lipids 60 years later: the Helsinki Birth Cohort study. Int J Epidemiol 2008; 37(2): 280-289.

15 Painter RC, Osmond C, Gluckman P, Hanson M, Phillips DI, Roseboom TJ. Transgenerational effects of prenatal exposure to the Dutch famine on neonatal adiposity and health in later life. Bjog 2008; 115(10): 1243-1249.

16 Thame M, Osmond C, Wilks RJ, Bennett FI, McFarlaneAnderson N, Forrester TE. Blood pressure is related to placental volume and birth weight. Hypertension 2000; 35(2): 662-667.

17 Marshall WA, Tanner JM. Variations in pattern of pubertal changes in girls. Arch Dis Child 1969; 44(235): 291-303.
18 Marshall WA, Tanner JM. Variations in the pattern of pubertal changes in boys. Arch Dis Child 1970; 45(239): 13-23.

19 Park SH, Shub C, Nobrega TP, Bailey KR, Seward JB. Two-dimensional echocardiographic calculation of left ventricular mass as recommended by the American Society of Echocardiography: correlation with autopsy and M-mode echocardiography. J Am Soc Echocardiogr 1996; 9(2): 119-128.

20 Palmieri V, Bella JN, Roman MJ, Gerdts E, Papademetriou V, Wachtell $\mathrm{K}$ et al. Pulse pressure/stroke index and left ventricular geometry and function: the LIFE Study. J Hypertens 2003; 21(4): 781-787.

21 Lind L, Andren B, Sundstrom J. The stroke volume/ pulse pressure ratio predicts coronary heart disease mortality in a population of elderly men. J Hypertens 2004; 22(5): 899-905.

22 Boyne MS, Thame M, Osmond C, Fraser RA, Gabay L, Reid $\mathrm{M}$ et al. Growth, body composition, and the onset of puberty: longitudinal observations in Afro-Caribbean Children. J Clin Endocrinol Metab 2010; 95(7): 3194-3200.

23 Randall OS, Westerhof N, van den Bos GC, Alexander B. Reliability of stroke volume to pulse pressure ratio for estimating and detecting changes in arterial compliance. J Hypertens Suppl 1986; 4(5): S293-S296.

24 Vijayakumar M, Fall CH, Osmond C, Barker DJ. Birth weight, weight at one year, and left ventricular mass in adult life. Br Heart J 1995; 73(4): 363-367.

25 Zureik M, Bonithon-Kopp C, Lecomte E, Siest G, Ducimetiere P. Weights at birth and in early infancy, systolic pressure, and left ventricular structure in subjects aged 8 to 24 years. Hypertension 1996; 27(3 Part 1): 339-345.

26 Mikkola K, Leipala J, Boldt T, Fellman V. Fetal growth restriction in preterm infants and cardiovascular function at five years of age. J Pediatr 2007; 151(5): 494-499, 499, e491-492.

27 Dekkers C, Treiber FA, Kapuku G, Van Den Oord EJ, Snieder H. Growth of left ventricular mass in African American and European American youth. Hypertension 2002; 39(5): 943-951.

28 Kumaran K, Fall CH, Martyn CN, Vijayakumar M, Stein C, Shier R. Blood pressure, arterial compliance, and left ventricular mass: no relation to small size at birth in south Indian adults. Heart 2000; 83(3): 272-277.

29 Dai S, Harrist RB, Rosenthal GL, Labarthe DR. Effects of body size and body fatness on left ventricular mass in children and adolescents: Project HeartBeat!. Am J Prev Med 2009; 37(1 Suppl): S97-S104.

30 Daniels SR, Kimball TR, Morrison JA, Khoury P, Witt S, Meyer RA. Effect of lean body mass, fat mass, blood pressure, and sexual maturation on left ventricular mass in children and adolescents. Statistical, biological, and clinical significance. Circulation 1995; 92(11): 3249-3254.

31 Levent E, Atik T, Darcan S, Ulger Z, Goksen D, Ozyurek AR. The relation of arterial stiffness with intrauterine growth retardation (IUGR). Pediatr Int 2009, 807-811.

32 Bradley TJ, Potts JE, Lee SK, Potts MT, De Souza AM, Sandor GG. Early changes in the biophysical properties of the aorta in pre-adolescent children born small for gestational age. J Pediatr 2009, 388-392.

33 Sakuragi S, Abhayaratna K, Gravenmaker KJ, O’Reilly C, Srikusalanukul W, Budge MM et al. Influence of adiposity and physical activity on arterial stiffness in 
healthy children: the lifestyle of our kids study. Hypertension 2009; 53(4): 611-616.

34 Mimoun E, Aggoun Y, Pousset M, Dubern B, Bougle D, Girardet JP et al. Association of arterial stiffness and endothelial dysfunction with metabolic syndrome in obese children. J Pediatr 2008; 153(1): 65-70.

35 Iannuzzi A, Licenziati MR, Acampora C, Salvatore V, De Marco D, Mayer MC et al. Preclinical changes in the mechanical properties of abdominal aorta in obese children. Metabolism 2004; 53(9): 1243-1246.

36 Collins RT, Somes GW, Alpert BS. Arterial stiffness is increased in American adolescents compared to Japanese counterparts. Pediatr Cardiol 2009; 30(6): 794-799.

37 Collins RT, Somes GW, Alpert BS. Differences in arterial compliance among normotensive adolescent groups: collins arterial compliance in adolescents. Pediatr Cardiol 2008; 29(5): 929-934.

38 Gluckman PD, Hanson MA, Cooper C, Thornburg KL. Effect of in utero and early-life conditions on adult health and disease. N Engl J Med 2008; 359(1): 61-73.

39 Giraud GD, Louey S, Jonker S, Schultz J, Thornburg KL. Cortisol stimulates cell cycle activity in the cardiomyocyte of the sheep fetus. Endocrinology 2006; 147(8): 3643-3649.

40 Barbera A, Giraud GD, Reller MD, Maylie J, Morton MJ, Thornburg KL. Right ventricular systolic pressure load alters myocyte maturation in fetal sheep. Am J Physiol Regul Integr Comp Physiol 2000; 279(4): R1157-R1164.

41 Martyn CN, Greenwald SE. Impaired synthesis of elastin in walls of aorta and large conduit arteries during early development as an initiating event in pathogenesis of systemic hypertension. Lancet 1997; 350(9082): 953-955.

42 Martyn CN, Greenwald SE. A hypothesis about a mechanism for the programming of blood pressure and vascular disease in early life. Clin Exp Pharmacol Physiol 2001; 28(11): 948-951.

43 Chung AW, Yang HH, Sigrist MK, Brin G, Chum E, Gourlay WA et al. Matrix metalloproteinase-2 and -9 exacerbate arterial stiffening and angiogenesis in diabetes and chronic kidney disease. Cardiovasc Res 2009; 84(3): 494-504.
44 Jiang B, Godfrey KM, Martyn CN, Gale CR. Birth weight and cardiac structure in children. Pediatrics 2006; 117(2): e257-e261.

45 Geelhoed JJ, Steegers EA, van Osch-Gevers L, Verburg BO, Hofman A, Witteman JC et al. Cardiac structures track during the first 2 years of life and are associated with fetal growth and hemodynamics: the Generation R Study. Am Heart J 2009; 158(1): 71-77.

46 Schieken RM, Schwartz PF, Goble MM. Tracking of left ventricular mass in children: race and sex comparisons: the MCV Twin Study. Medical College of Virginia. Circulation 1998; 97(19): 1901-1906.

47 de Simone G, Devereux RB, Daniels SR, Koren MJ, Meyer RA, Laragh JH. Effect of growth on variability of left ventricular mass: assessment of allometric signals in adults and children and their capacity to predict cardiovascular risk. J Am Coll Cardiol 1995; 25(5): 1056-1062.

48 Schack-Nielsen L, Molgaard C, Larsen D, Martyn C, Michaelsen KF. Arterial stiffness in 10-year-old children: current and early determinants. Br J Nutr 2005; 94(6): 1004-1011.

49 Farpour-Lambert NJ, Aggoun Y, Marchand LM, Martin XE, Herrmann FR, Beghetti M. Physical activity reduces systemic blood pressure and improves early markers of atherosclerosis in pre-pubertal obese children. J Am Coll Cardiol 2009; 54(25): 2396-2406.

50 Cruickshank JK, Rezailashkajani M, Goudot G. Arterial stiffness, fatness, and physical fitness: ready for intervention in childhood and across the life course? Hypertension 2009; 53(4): 602-604.

51 Fernhall B, Agiovlasitis S. Arterial function in youth: window into cardiovascular risk. J Appl Physiol 2008; 105(1): 325-333.

52 Sherva R, Miller MB, Lynch AI, Devereux RB, Rao DC, Oberman A et al. A whole genome scan for pulse pressure/stroke volume ratio in African Americans: the HyperGEN study. Am J Hypertens 2007; 20(4): 398-402.

53 Pavlopoulos H, Nihoyannopoulos P. Pulse pressure/ stroke volume: a surrogate index of arterial stiffness and the relation to segmental relaxation and longitudinal systolic deformation in hypertensive disease. Eur J Echocardiogr 2009; 10(4): 519-526. 